\begin{tabular}{|c|c|}
\hline Title & A uxiliary Supply-A ssisted 12-Pulse Phase-Controlled Rectifiers With Reduced Input Current Harmonics \\
\hline Author(s) & Fukuda, Shoji; Hiei, Issei \\
\hline Citation & $\begin{array}{l}\text { IEEE Transactions on Industry A pplications, 44(1), 205-212 } \\
\text { https://doi.org/10.1109/ IA .2007.912805 }\end{array}$ \\
\hline Issue Date & $2008-01$ \\
\hline Doc URL & http:/hdl.handle.net/2115/33045 \\
\hline Rights & $\begin{array}{l}\text { () 2008 IEEE. Personal use of this material is permitted. However, permission to reprint/republish this material for } \\
\text { advertising or promotional purposes or for creating new collective works for resale or redistribution to servers or lists, } \\
\text { or to reuse any copyrighted component of this work in other works must be obtained from the IEEE. }\end{array}$ \\
\hline Type & article \\
\hline File Information & 04439770.pdf \\
\hline
\end{tabular}

Instructions for use 


\title{
Auxiliary Supply-Assisted 12-Pulse Phase-Controlled Rectifiers With Reduced Input Current Harmonics
}

\author{
Shoji Fukuda, Senior Member, IEEE, and Issei Hiei
}

\begin{abstract}
Three-phase thyristor rectifiers have been used in industries for obtaining a variable de voltage, but they have a problem of including large lower-order harmonics in the input currents. For high-power applications, a 12-pulse configuration is useful for reducing the harmonics, but it still includes the $(12 m \pm 1)$ th $(m$ : integer) harmonics. In order to further reduce the harmonics, this paper proposes to insert an auxiliary supply producing a square wave voltage to the dc bus of a 12-pulse phase-controlled rectifier. Theoretical investigation to reduce harmonics is presented, and a strategy to control the auxiliary supply voltage based on pulsewidth-modulation is proposed. Reduction in the current harmonics is verified by simulation and experimental results. The voltampere (VA) rating of the auxiliary supply is about $5 \%$ of the rectifier output.
\end{abstract}

Index Terms-AC-DC power conversion, power conversion harmonics, power electronics, thyristor applications, thyristor converters.

\section{INTRODUCTION}

D IODE rectifiers and phase-controlled thyristor rectifiers are very popular in several industrial applications: chemical processes, dc arc furnaces, HVdc transmission systems, adjustable speed ac drives, etc. [1]. However, such rectifiers include large lower-order harmonics in the input currents and do not meet harmonic current content restrictions, as imposed by several international standards such as IEC 61000 and IEEE 519 [2]-[4]. For high-power applications, installation of passive filters is mandatory [5] to reduce the current harmonics introduced by the rectifier to the power system, but they make the overall rectifier system bulky and expensive. Another solution for the harmonic reduction is the utilization of active power filters [6], [7], but it is a very expensive solution.

Diode rectifiers with special configurations using additional switching devices and/or passive components [8]-[12] were proposed to reduce harmonics, but they are too complicated to be employed in high-power applications. A 12-pulse configuration [1], [5], [13]-[15] consisting of two sets of six-pulse rectifiers is popular for high-power applications. This enables to offset the harmonic components such as the fifth and seventh produced by each of the two rectifiers, but the $(12 m \pm 1)$ th $(m$ : integer) harmonics still remain in the resultant input currents. It is usual to use passive power filters tuned to harmonics 11 and

Paper IPCSD-07-049, presented at the 2005 Industry Applications Society Annual Meeting, Hong Kong, October 2-6, and approved for publication in the IEEE TRANSACTIONS ON INDUSTRY APPLICATIONS by the Electrostatic Processes Committee of the IEEE Industry Applications Society. Manuscript submitted for review January 27, 2006 and released for publication July 16, 2007.

The authors are with the Graduate School of Information Science and Technology, Hokkaido University, Sapporo 060-0808, Japan (e-mail: fukudasy@k7.dion.ne.jp).

Digital Object Identifier 10.1109/TIA.2007.912805
13, and an additional high-pass filter to eliminate the remaining harmonics.

Several strategies [16]-[22] were proposed for 12-pulse diode rectifiers to further reduce the $(12 m \pm 1)$ th harmonics. Miyairi et al. [16] proposed the use of an interphase reactor equipped with multiple switched taps. Choi et al. [17] proposed a parallel connected diode rectifier with an active interphase reactor. Masukawa and Iida [18] proposed to use an interphase reactor having secondary windings with an auxiliary circuit, and Nishida and Nakaoka [19] proposed series-connected double three-phase diode rectifiers with auxiliary circuits. A problem of them is that the operation of the auxiliary circuit is very complicated.

Fujita and Akagi [20] proposed to use a series active filter to a 12-pulse rectifier, and Cheng et al. [21] proposed to use a square-wave inverters-based dominant harmonic active filter. A problem of them is an expensive system because they employ an active power filter.

Okuyama [22] proposed to insert an auxiliary voltage supply (AVS) to the middle dc bus of a cascade-connected capacitorinput 12-pulse rectifier. Fukuda and Ohta proposed the control strategy [23] of an AVS for the same configuration in [22], and demonstrated the reduction in the 11th and 13th harmonics in the resultant input current. However, since these eight references treat 12-pulse diode rectifiers, a novel strategy is required for treating 12-pulse phase controlled rectifiers having a dc voltage control function.

Iwaji and Okuyama [24] proposed to expand the same idea in [22] to a cascade-connected capacitor-input 12-pulse thyristor rectifier, but the control method of an AVS was not established. Fukuda and Ohta tried to expand the application of the method in [23] to 12-pulse phase-controlled thyristor rectifiers to reduce the input current harmonics. There are several configurations of 12-pulse thyristor rectifiers, but the method is applicable to only two configurations illustrated in Fig. 1(a) and (b). Fig. 1(a) is a parallel-connected choke-input type and Fig. 1(b) is a cascadeconnected capacitor-input type. Fukuda and Hiei applied the method to a cascade-connected 12-pulse thyristor rectifier [25] and revealed that the AVS was effective only in a narrow output voltage range. This is because the insertion of AVS to a 12pulse rectifier is effective only if the dc current of the original six-pulse rectifier flows continuously. The dc current $i_{\text {rec } 1}$ or $i_{\text {rec2 }}$ in Fig. 1(b) with $V_{i}=0$ flows continuously only in a very narrow firing angle range, say, $\alpha=0-20^{\circ}$ because the rectifier is of capacitor-input type. In contrast, the current $i_{\mathrm{rec} 1}$ or $i_{\mathrm{rec} 2}$ in Fig. 1(a) with $V_{i}=0$ flows continuously in a wide firing angle range because the rectifier is of choke-input type.

This paper deals with a parallel-connected choke-input 12pulse thyristor rectifier, and inserts an AVS to each of the dc 


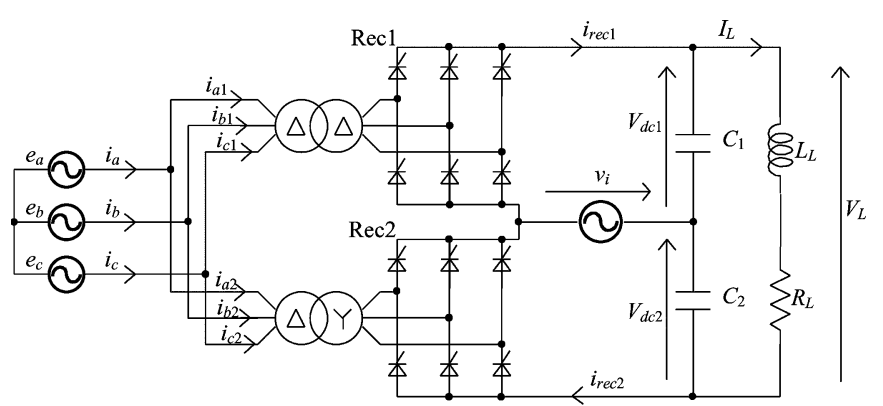

(a)

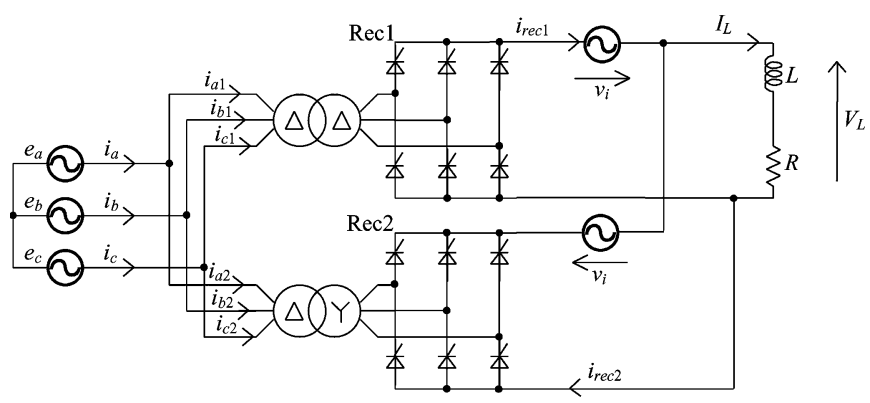

(b)

Fig. 1. Configurations of phase-controlled 12-pulse thyristor rectifier with AVS $v_{i}$. (a) Choke-input type. (b) Capacitor-input type.

bus, as shown in Fig. 1(a) to reduce the harmonics, especially the 11th and 13th components. It presents theoretical investigations on the principle of reducing the harmonics. It also presents a method to control the AVS voltage in relation to the load current and firing angle of the thyristors. It is shown that AVS is effective almost over a whole output voltage range. Finally, the usefulness of the proposed configuration and control method is verified by simulation studies and experimental results.

In order to reduce input current harmonics, Tanaka et al. [26] proposed the insertion of an interphase reactor having an appropriate leakage inductance to the dc bus of a 12-pulse chokeinput phase-controlled rectifier. It is shown that their idea is included in this paper as a special case.

\section{Circuit Configuration AND Operation}

Fig. 1(a) shows the configuration of a phase-controlled 12pulse thyristor rectifier with AVSs proposed in this paper. It consists of two three-phase thyristor rectifiers, Rec1 and Rec2, connected in parallel; and two AVSs having a voltage $v_{i}$. The Rec1 and Rec2 are supplied from identical two sets of threephase voltage systems having a phase difference of $30^{\circ}$ each other. A conventional 12-pulse configuration includes an interphase reactor in the dc circuit to equally share the dc currents $I_{L}$ in Rec1 and Rec2, but it is not necessary with the proposed configuration because $i_{\text {rec1 }}$ and $i_{\text {rec } 2}$ flow alternately.

Assume that the dc output currents $i_{\text {rec1 }}$ and $i_{\text {rec2 } 2}$ were triangular with a frequency six times that of the utility having a dc component $I_{L} / 2$, as shown in Fig. 2(a) and (b). Then, the input currents of the each rectifier, $i_{a 1}$ and $i_{a 2}$, and the resultant input current $i_{a}\left(=i_{a 1}+i_{a 2}\right)$ would be as shown in Fig. 2(c)-(e), re- (a)

(b)

(c)

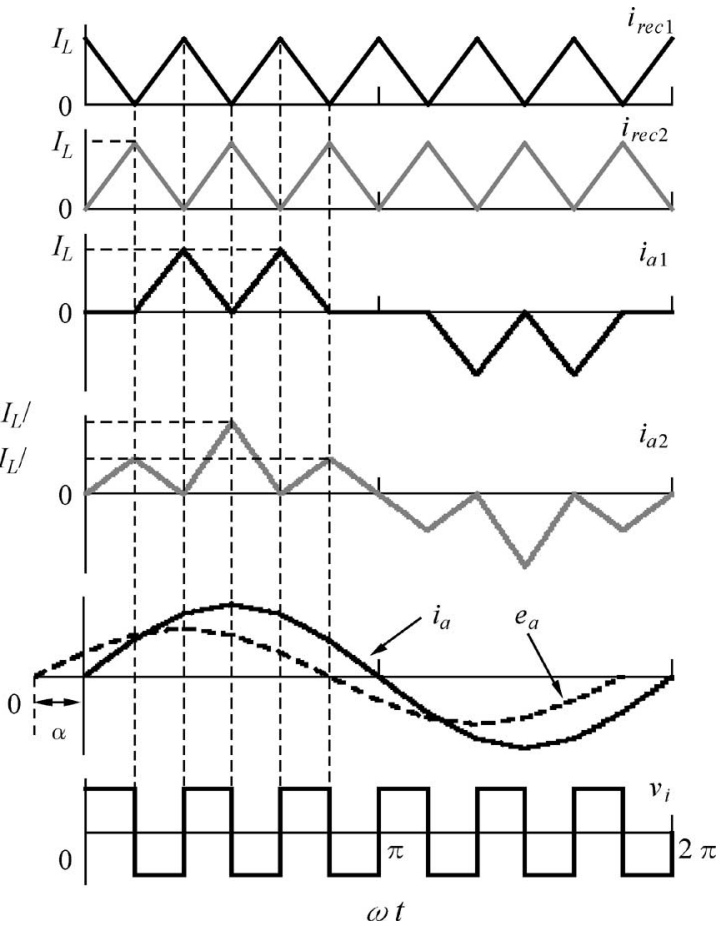

Fig. 2. Hypothetical 12-pulse rectifier current waveforms with AVS.

spectively. From the figure, one can observe that the harmonics almost disappear in $i_{a}$. Total harmonic distortion (THD) of $i_{a}$ is as low as $1.06 \%$.

In order to shape $i_{\text {rec1 } 1}$ and $i_{\text {rec2 }}$ as indicated in Fig. 2(a)(b), two AVSs, having an identical voltage $v_{i}$, are introduced. They are inserted in each dc bus of Rec1 and Rec2, as shown in Fig. 1(a) and generate a square-wave voltage with adjustable amplitude $V_{i}$. The AVS is synchronized with the triggering signals of the thyristors, and has a frequency six times that of the mains voltage, as shown in Fig. 2(f). In the figure, $\alpha$ denotes the firing angle of the thyristors and $v_{i}$ changes its polarity synchronized with each commutation instant of the thyristors.

\section{ANALYSIS OF OPERATION}

Defining the following two sets of three-phase mains voltage systems, $e_{1}$ and $e_{2}$, for Rec 1 and Rec 2 , respectively. They are illustrated in Fig. 3.

$$
\begin{aligned}
& e_{a 1}=E \sin \left(\omega t+\frac{2 \pi}{3}\right) \quad e_{a 2}=E \sin \left(\omega t+\frac{5 \pi}{6}\right) \\
& e_{b 1}=E \sin \omega t \quad e_{b 2}=E \sin \left(\omega t+\frac{\pi}{6}\right) \\
& e_{c 1}=E \sin \left(\omega t-\frac{2 \pi}{3}\right) \quad e_{c 2}=E \sin \left(\omega t-\frac{\pi}{2}\right) .
\end{aligned}
$$

Consider a time period, $\theta=\alpha$ to $\theta=\alpha+\pi / 6$ with $\theta=\omega t$. The commutation in $\operatorname{Rec} 2$ starts at $\theta=\alpha$ from phase- $a 2$ to phase- $b 2$, and it finishes instantaneously as explained later. Fig. 4 gives the equivalent dc circuit, and the following equation holds.

$$
2 x \frac{d\left(i_{\mathrm{rec} 1}-i_{\mathrm{rec} 2}\right)}{d \theta}=2 v_{i}-e_{11}+e_{22}
$$




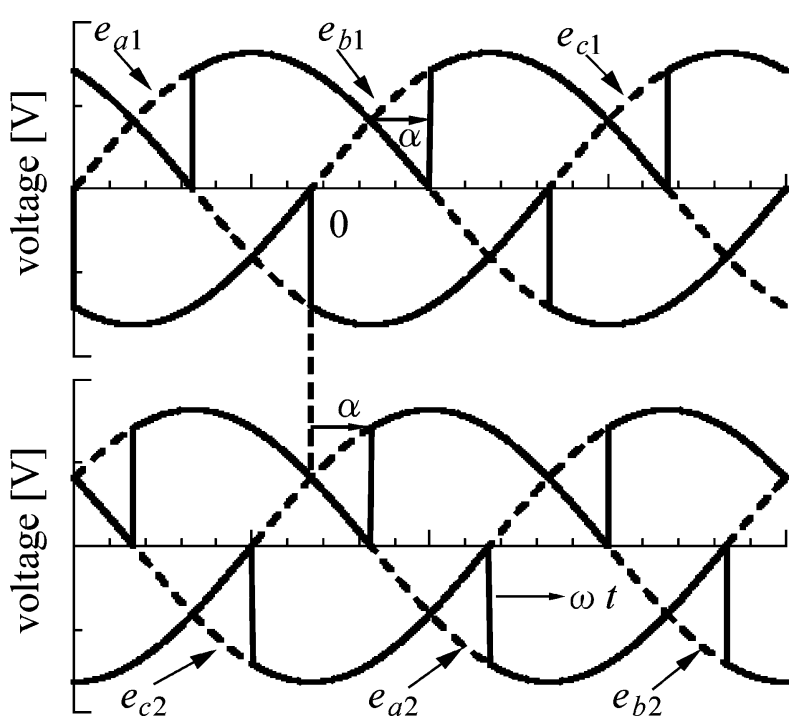

Fig. 3. Two sets of three-phase mains voltages, $e_{a 1}-e_{c 1}$ for $\operatorname{Rec} 1$ and $e_{a 2}-$ $e_{c 2}$ for $\operatorname{Rec} 2$.

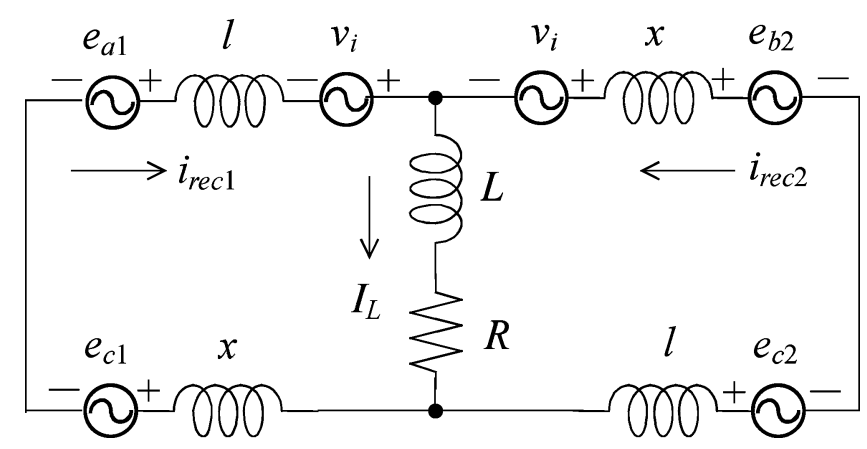

Fig. 4. Equivalent dc circuit during $\theta=\alpha$ to $\alpha+\pi / 6$.

$$
e_{11} \equiv\left(e_{a 1}-e_{c 1}\right), e_{22} \equiv\left(e_{b 2}-e_{c 2}\right)
$$

where $x=\omega l$ denotes the leakage reactance of the transformer per phase, and $e_{11}$ and $e_{22}$ represent the instantaneous dc voltages of Rec1 and Rec2, respectively. Since the dc load current $I_{L}\left(=i_{\text {rec } 1}+i_{\text {rec } 2}\right)$ is constant, the following equations hold.

$$
\begin{gathered}
4 x \frac{d i_{\mathrm{rec} 2}}{d \theta}=V_{S} \\
V_{S} \equiv 2 v_{i}+2 \sqrt{3} E \sin \left(\frac{\pi}{12}\right) \sin \left(\omega t-\frac{\pi}{12}\right) .
\end{gathered}
$$

If the voltage $V_{S}$ is constant, (2) indicates that $i_{\text {rec2 }}$ increases linearly with time. Assume that the variations in $i_{\text {rec2 } 2}$ were as shown in Fig. 5, as indicated in Fig. 2(b). The initial condition would be $i_{\text {rec } 2}=0$ at $\theta=\alpha$, and the final condition would be $i_{\mathrm{rec} 2}=I_{L}$ at $\theta=\alpha+\pi / 6$. Hence, the following relation is obtained.

$$
V_{S}=\left(\frac{24}{\pi}\right) x I_{L}
$$

In the same manner, one can understand that $i_{\text {rec } 1}$ decreases linearly with time in the same period, as shown in Fig. 5. Thus,

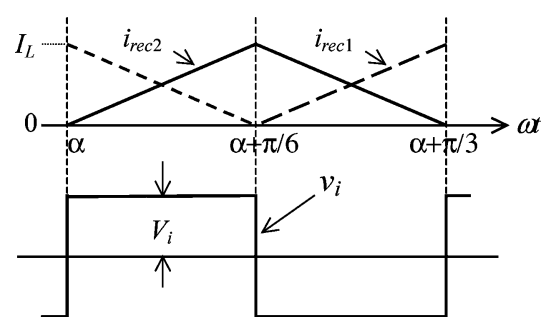

Fig. 5. Waveforms of dc output currents with AVS voltage $v_{i}$.

the voltage $V_{S}$ forces $i_{\text {rec1 }}$ and $i_{\text {rec2 }}$ to vary in a triangular shape indicated in Fig. 2(a) and (b), respectively.

For simplicity, assume that the second terms of $V_{S}$ in (3) is constant, averaging it over the period $\theta=\alpha$ to $\alpha+\pi / 6$. Then, the amplitude of $v_{i}$ will be given by

$$
\begin{aligned}
V_{i} & =\left(\frac{12}{\pi}\right) x I_{L}-\left(\frac{6 \sqrt{3}}{\pi}\right)\left(1-\frac{\sqrt{3}}{2}\right) E \sin \alpha \\
& =\left(\frac{12}{\pi}\right) x I_{L}-0.443 E \sin \alpha .
\end{aligned}
$$

In the following period, since $i_{\text {rec } 2}$ is forced to decrease from $I_{L}$ to $0, \theta=\alpha+\pi / 6$ to $\alpha+\pi / 3$, the right-hand side of (2) must be negative, $-V_{S}$. The average value of the second term of $V_{S}$ in (3) is the same as that in the previous period but takes a negative sign. Hence, $v_{i}$ should be a square wave with an amplitude $V_{i}$, and changes its polarity at every commutation instant of the thyristors. The commutation takes place at every $60^{\circ}$ in Rec 1 and Rec 2 alternately. Thus, the frequency of $v_{i}$ must be six times that of the mains frequency. Equation (5) is very important, and it requires that the amplitude $V_{i}$ should be controlled in relation to the load current $I_{L}$ and the firing angle $\alpha$, in order to get the best results in terms of harmonic distortion. ${ }^{1}$ It is interesting that there is a special combination between $I_{L}$ and $\alpha$, which makes $V_{i}=0$ or minimizes THD without AVS. This coincides with the conclusion in [26]. The following commutation starts at $\theta=\alpha+\pi / 6$ in Rec1. It finishes immediately because $i_{\mathrm{rec} 1}$ is already reduced to zero at that instant as Fig. 5 indicates. The thyristors commutate instantaneously.

The authors confirmed that the proposed harmonic reduction method is also effective to an inverter mode of operation. However, practical applications of 12-pulse choke-input type rectifiers [1], [5] do not require an inverter mode of operation.

${ }^{1}$ In order for AVS to maintain an optimal voltage at any load conditions, feed-forward control of $V_{i}$ is required with the detection of the load current $I_{L}$ The voltage $V_{i}$ is adjusted according to (5) as a function of $\alpha$ and $I_{L}$. It is easy because a linear relation holds between $V_{i}$ and $I_{L}$. 


\section{Characteristics OF PROPOSED ReCtifieR}

\section{A. DC Output Voltage and Output Power}

The average dc output voltage $V_{L 0}$ and output power $P_{\text {out }}$ of the rectifier will be

$$
V_{L 0}=\left(\frac{3 \sqrt{3}}{\pi}\right) E \cos \alpha \quad P_{\text {out }}=\left(\frac{3 \sqrt{3}}{\pi}\right) E I_{L} \cos \alpha .
$$

If AVS is not used, at light load, either Rec1 or Rec2 having a higher instantaneous dc voltage provides the dc current to the load for a $30^{\circ}$-period and the rest stops conducting the dc current, but at heavy load, both Rec1 and Rec2 provide the dc current simultaneously. If AVS is used, Rec 1 and Rec 2 provide the dc current simultaneously, but the current of extinguishing thyristor is reduced to zero at every commutation instant. The average dc voltage $V_{L 0}$ is exactly proportional to $\cos \alpha$ because no current overlap occurs at thyristor commutation. Accordingly, the proposed rectifier provides a slightly lower dc average voltage than a conventional 12-pulse rectifier.

\section{B. Volt-Ampere Rating of AVS}

From (5), the amplitude of AVS $V_{i}$ depends on $\alpha$ and $I_{L}$. It is obvious that the maximum volt-ampere (VA) will occur at $\alpha=$ 0 , because it provides the highest dc voltage and current. Thus, one has

$$
V_{i}=\left(\frac{12}{\pi}\right) x I_{L}
$$

Since rms values of the rectifier resultant input current $I$ and the current flowing through $\operatorname{AVS} I_{i}$ are

$$
I=\left(\sqrt{\frac{2}{3}}\right) I_{L}=0.816 I_{L} \quad I_{i}=\frac{I_{L}}{\sqrt{3}}=0.577 I_{L}
$$

the VA rating of AVS will be given by

$$
\mathrm{VA}_{i}=\left(\frac{12}{\pi}\right) x I_{L} I_{i}=\left(\frac{12}{\pi}\right) x_{\mathrm{pu}} E \frac{I_{L}}{\sqrt{2}}=3.82 x_{\mathrm{pu}} E I_{L}
$$

where $x_{\mathrm{pu}}$ denotes the per-unit based leakage reactance of the transformer per phase. The ratio of the AVS rating to the rectifier output power will be

$$
\frac{\mathrm{VA}_{i}}{P_{\text {out }}(\alpha=0)}=\left(\frac{4}{\sqrt{3}}\right) x_{\mathrm{pu}}=2.31 x_{\mathrm{pu}} .
$$

If $x_{\mathrm{pu}}=2 \%$, the VA rating of AVS would be less than $5 \%$ of the 12-pulse rectifier output.

It is noted that an interphase reactor is unnecessary with the proposed rectifier. It results in increasing the VA rating of AVS, because the inductance of an interphase reactor increases the reactance $x$ in (1).

\section{Auxiliary Voltage Supply}

The author used a single-phase pulse width modulation (PWM) inverter illustrated in Fig. 6 for AVS with an adjustable output voltage. The AVS feeds voltage $v_{i}$ to Rec1 and Rec2 through a transformer having two identical secondary windings. The amplitude $V_{i}$ is adjusted according to (5) depending

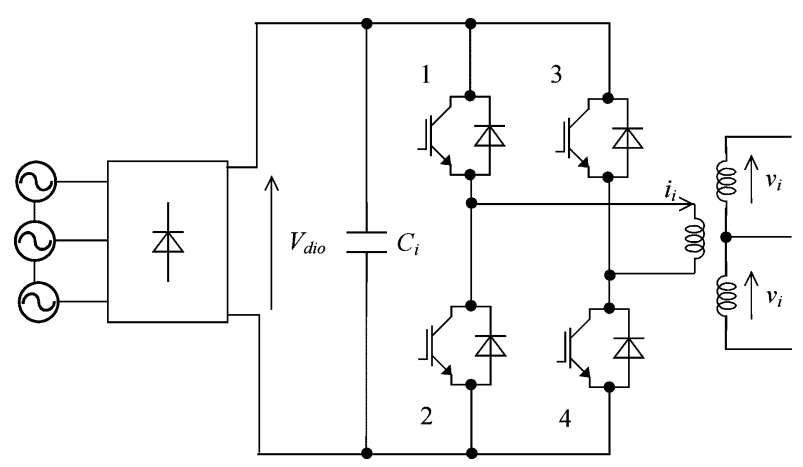

Fig. 6. Configuration of AVS.

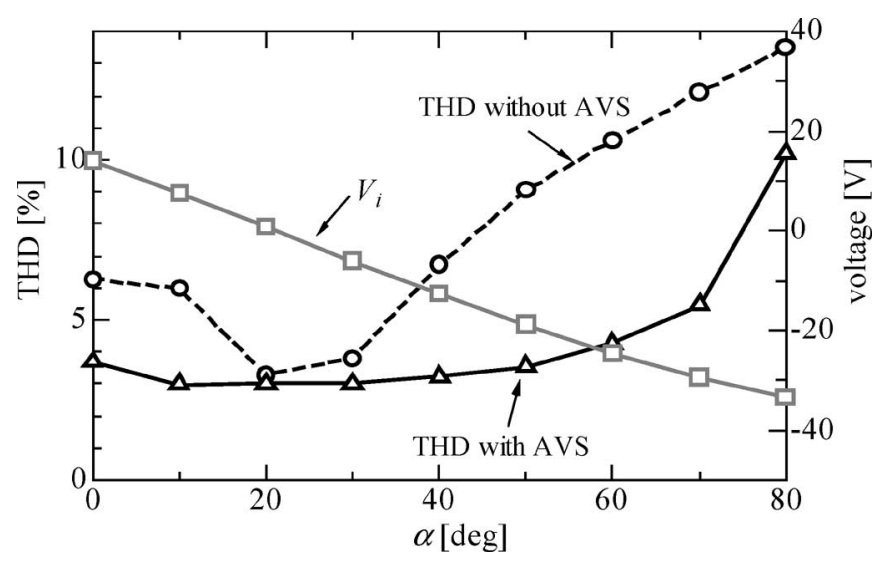

Fig. 7. Improvement in input current THD by inserting AVS with optimal amplitude.

on the load current $I_{L}$ and the firing angle $\alpha$. The output power of AVS is calculated as

$$
P_{\text {iout }}=\left(\frac{6}{\pi}\right) \int_{\alpha}^{\alpha+\pi / 6} V_{i}\left(i_{\text {rec } 2}-i_{\text {rec } 1}\right) d \theta=0 .
$$

There is no net power flow between the rectifier and AVS. The diode rectifier charges the dc capacitor $C_{i}$ just at starting. Therefore, the input current of the diode rectifier at steady state would be zero if the capacitor $C_{i}$ is large enough. Thus, it would not distort the mains currents. But, in practice, as some resistance components exist in the transformer windings, there is a slight power flow between the rectifier and AVS.

\section{Simulation Results}

Simulation studies are carried out with the parameters listed in Table I. It is noted that the DC load resistance $R$ is kept constant with this simulation.

The relation between optimal $V_{i}$ that minimizes THD of the resultant input current and $\alpha$ is illustrated in Fig. 7. Also, the comparison of THD with and without AVS is presented in Fig. 7. If $V_{i}$ is controlled with $\alpha$, as indicated in the figure, THD is less than $5 \%$ over a wide adjustable output voltage range, $\alpha=0$ $60^{\circ}$. It is obvious that AVS is effective on reducing harmonic distortion of the rectifier input currents. It is interesting that if $\alpha=20^{\circ}$, THD is minimized without AVS. This is because with 
TABLE I

PARAMETERS USED FOR SimULATION

\begin{tabular}{lcc}
\hline Rectifier output & & $2.5 \mathrm{~kW}$ \\
\hline Line-to-line voltage in RMS & & $100 \mathrm{~V}$ \\
& & \\
\hline Frequency & $f$ & $50 \mathrm{~Hz}$ \\
\hline Leakage inductance of Tr. & $l$ & $0.638 \mathrm{mH}$ \\
& $x$ & $2.5 \%$ \\
\hline Resistance of Tr. & & $0.883 \Omega$ \\
\hline DC load inductance & $L$ & $50[\mathrm{mH}]$ \\
\hline DC load resistance & $R$ & $6.5[\Omega]$ \\
\hline
\end{tabular}

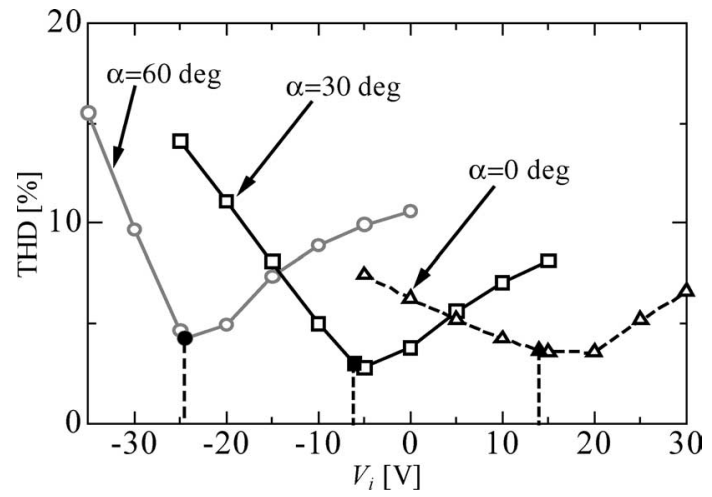

Fig. 8. Dependency of current THD on amplitude of AVS. (a) Without AVS. (b) With AVS.

the parameters given in Table I, it happened that $V_{S}$ satisfied (4) without AVS (or with $V_{i}=0$ ) at $\alpha=20^{\circ}$.

Fig. 8 demonstrates how $V_{i}$ affects on THD of the input current. The $V_{i}$ values given by (5) are represented with dotted lines. One can see that (5) gives almost the exact $V_{i}$ values that minimize current THD. Optimal $V_{i}$ strongly depends on the firing angle $\alpha$ and the load current $I_{L}$. It will be positive as well as negative.

Fig. 9(a) and (b) show the comparison of current waveforms with and without AVS under $\alpha=60^{\circ}$. If AVS is not used, the dc output currents $i_{\text {rec1 }}$ and $i_{\text {rec2 } 2}$ flow alternately, because either Rec1 or Rec2 having a higher instantaneous dc output voltage conducts the dc current to the load for a $30^{\circ}$-period and the rest stop conducting current. Hence, $i_{a 1}$ and $i_{a 2}$ also flow alternately. ${ }^{2}$ Current THD is $10.6 \%$. If AVS with optimal $V_{i}=-24.8 \mathrm{~V}$ is inserted, however, the dc output currents flow simultaneously. Current THD is improved to $4.64 \%$.

Frequency spectra of $i_{a}$ with and without AVS are compared in Fig. 10. One can observe that the 11th and 13th harmonics are drastically reduced if AVS is used.

Fig. 11 illustrates voltage and current waveforms at various locations under $\alpha=30^{\circ}$ when an optimal AVS voltage $v_{i}$, shown

\footnotetext{
${ }^{2}$ If the load is heavier, $i_{\mathrm{rec} 1}$ and $i_{\mathrm{rec} 2}$ flow simultaneously and continuously. Then, $i_{a 1}$ and $i_{a 2}$ flow simultaneously as well. The AVS is also effective in this case.
}
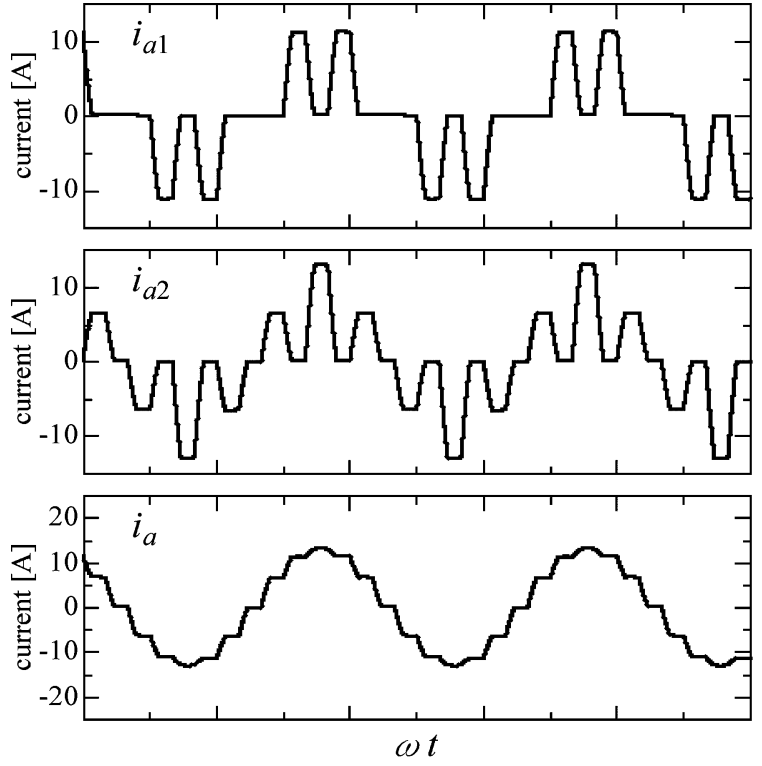

(a)
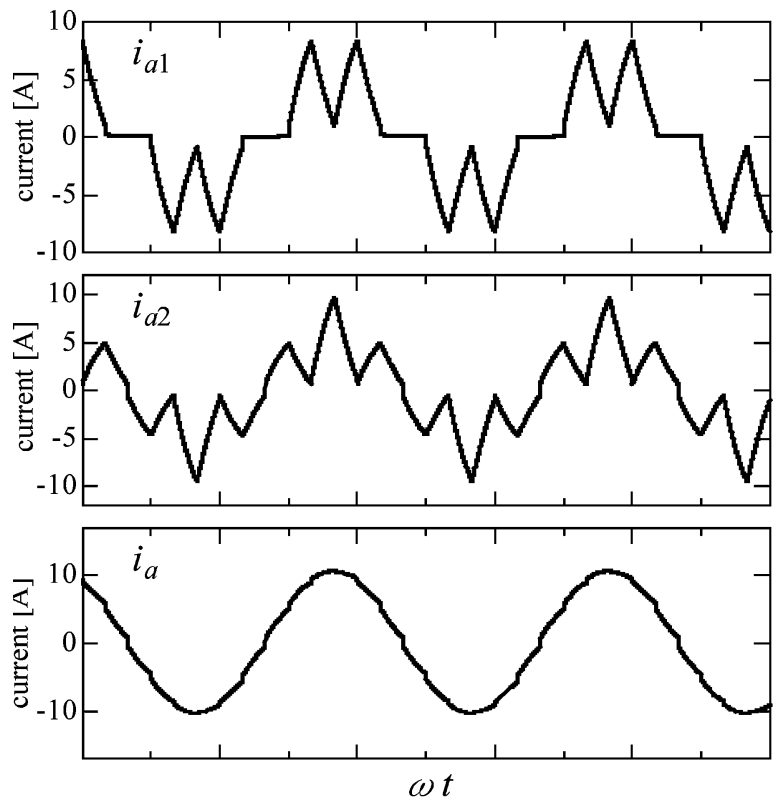

(b)

Fig. 9. Input current waveforms at $\alpha=\pi / 3$.

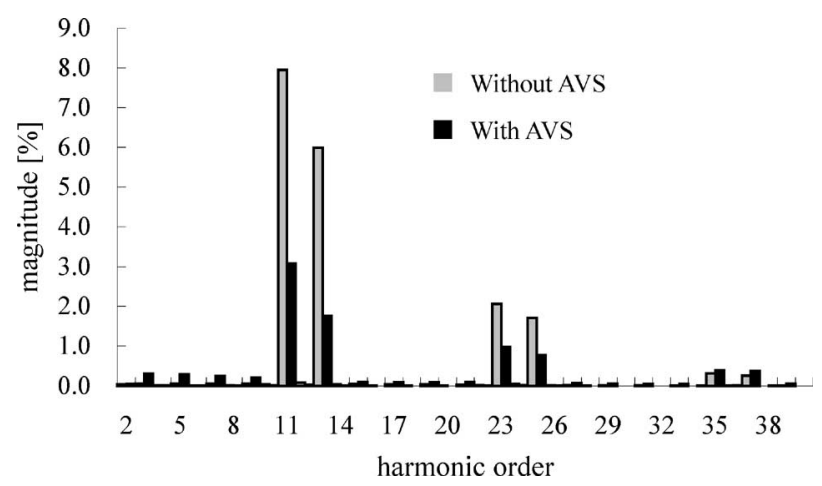

Fig. 10. Comparison of input current frequency spectra with and without AVS. 
(a)

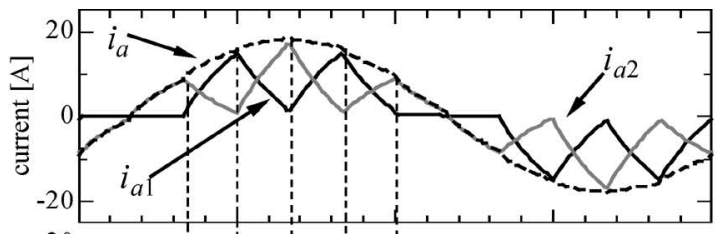

(b)

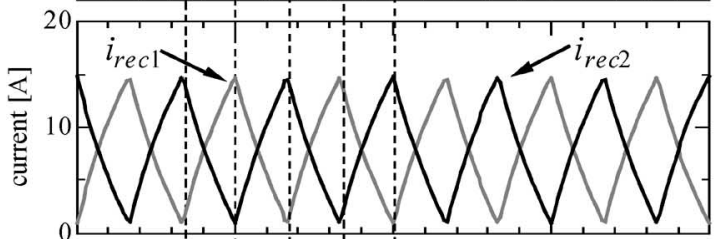

(c)

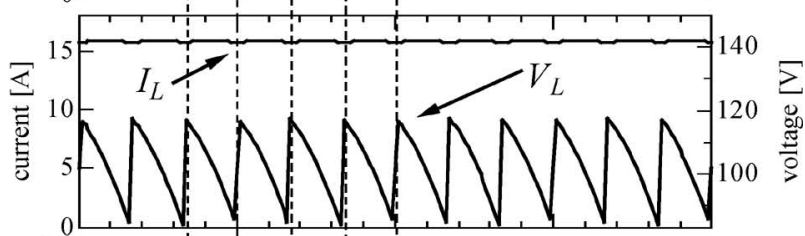

(d)

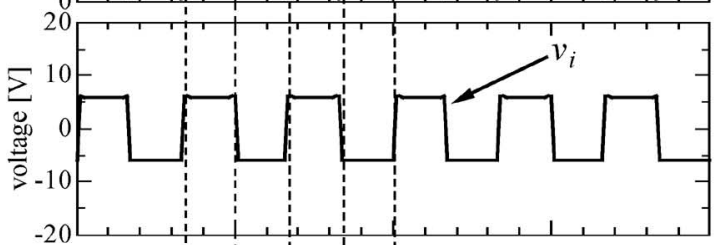

(e)

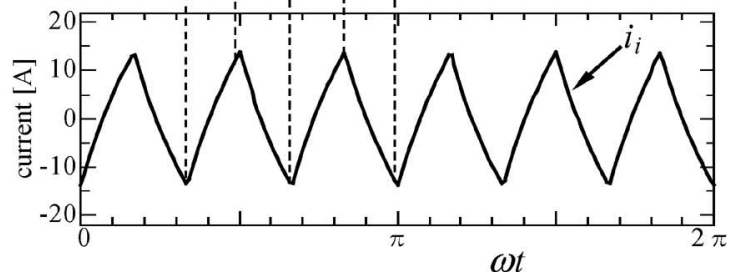

Fig. 11. Voltage and current waveforms at $\alpha=\pi / 6$.

in Fig. 11(d), is inserted. The current $i_{a 1}, i_{a 2}$, and $i_{a}$ are shown in Fig. 11(a). THD of $i_{a}$ is reduced to 2.8\%. The load current $I_{L}$ and instantaneous dc voltage $V_{L}$ are also shown in Fig. 11(c). One can confirm that $I_{L}$ is ripple-free, and the current overlap between two phases, which occurs at every commutation of thyristors with conventional 12-pulse rectifiers, is not observed in the $V_{L}$ waveform. The AVS current, $i_{i}=i_{\mathrm{rec} 1}-i_{\mathrm{rec} 2}$, is also shown in Fig. 11(e).

Twelve-pulse choke-input thyristor rectifiers have been used for large current applications such as dc arc furnaces and copper refining industries [1], [5]. If insulated-gate bipolar transistor (IGBT) modules of $V_{\mathrm{CE}}=1700 \mathrm{~V}$ and $I_{C}=2400 \mathrm{~A}$ [27] were used, a 1-MVA AVS could be built. Then, it could be employed for, e.g., a copper refining system of 20-MVA.

\section{EXPERIMENTAL RESULTS}

Experiment was carried out under the parameters listed in Table II. Two three-phase transformers having a turns-ratio 2:1 and $2: 1 / \sqrt{3}$ were used for the 12-pulse phase-controlled rectifier. Measured current waveforms at various locations without and with AVS are compared under $\alpha=60^{\circ}$ in Figs. 12 and 13, respectively .

Fig. 12(a) shows that if AVS is not used, Rec 1 and Rec2 conduct currents $i_{\text {rec1 }}$ and $i_{\text {rec2 }}$ alternately, but Fig. 13(a) shows that
TABLE II

PARAMETERS OF EXPERIMENTAL SETUP

\begin{tabular}{lcc}
\hline Rectifier output & & $2.5 \mathrm{~kW}$ \\
\hline $\begin{array}{l}\text { Line-to-line utility voltage } \\
\text { in RMS }\end{array}$ & $\sqrt{3} E$ & $200 \mathrm{~V}$ \\
\hline Frequency & $f$ & $50 \mathrm{~Hz}$ \\
\hline Leakage inductance of Tr. & $l$ & $0.425 \mathrm{mH}$ \\
referred to secondary & $x$ & $1.82 \%$ \\
\hline Resistance of Tr. referred to & $r$ & $0.221 \Omega$ \\
secondary & & \\
\hline DC load inductance & $L$ & $50 \mathrm{mH}$ \\
\hline DC load resistance & $R$ & $8.0 \Omega$ \\
\hline DC input voltage of AVS & $V_{d \mathrm{io}}$ & $80 \mathrm{~V}$ \\
\hline
\end{tabular}
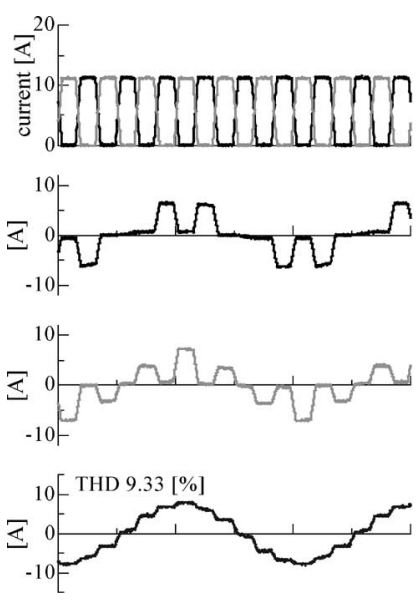

Fig. 12. Current waveforms without AVS at $\alpha=\pi / 3$.

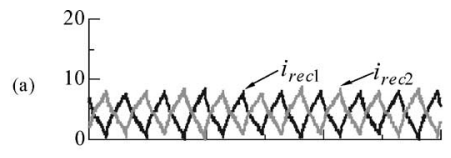

(b)

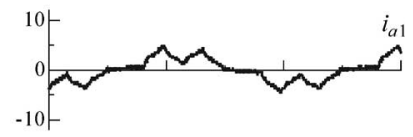

(c)

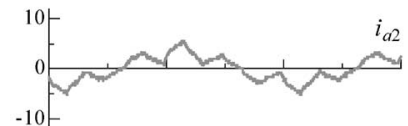

(d)

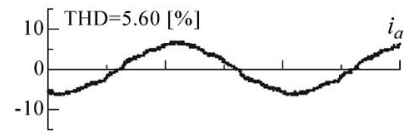

(e)

Fig. 13. Current and voltage waveforms with AVS at $\alpha=\pi / 3$.

they conduct current simultaneously if AVS is used. Fig. 13(b) and (c) show currents $i_{a 1}$ and $i_{a 2}$, respectively, when AVS was used. Both currents are similar to the simulation results given in Fig. 2(c) and (d), respectively.

Figs. 12(d) and 13(d) show the resultant input current $i_{a}$. Since the dc output voltage decreases if AVS is used, $i_{a}$ with 


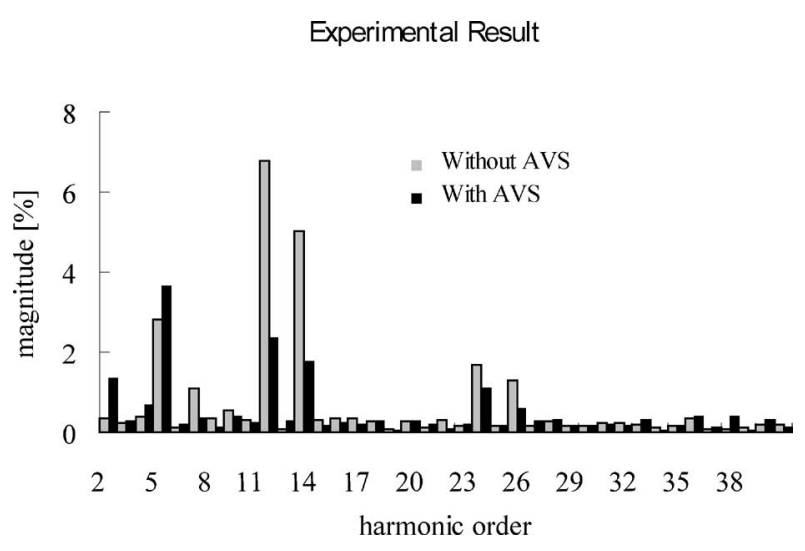

Fig. 14. Comparison of measured input current frequency spectra with and without AVS at $\alpha=\pi / 3$.

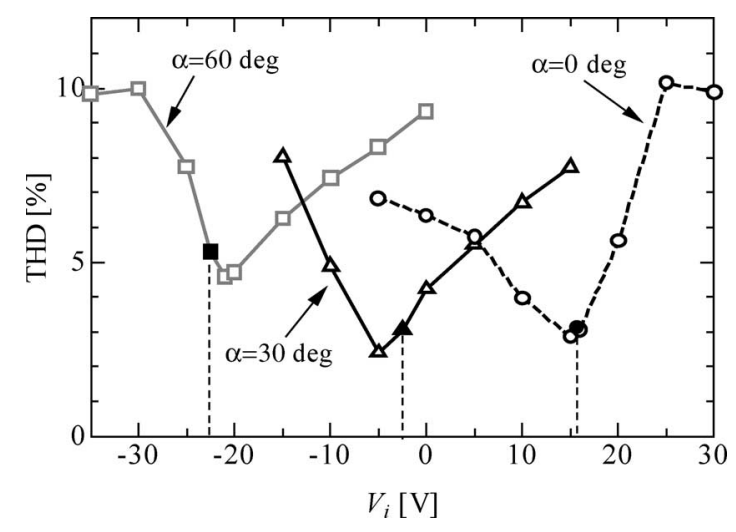

Fig. 15. Dependency of measured current THD on amplitude of AVS.

AVS was smaller than that without AVS. If AVS was not used, THD of $i_{a}$ was $9.33 \%$, but it was improved to $5.30 \%$ if AVS was used.

Fig. 13(e) shows the AVS voltage. It seems a square wave with the amplitude $50 \mathrm{~V}$, but, actually, it is a PWM shape and is equivalent to a square wave with the amplitude $V_{i}=-22.5 \mathrm{~V}$.

Fig. 14 shows frequency spectra of $i_{a}$. One can observe that AVS remarkably reduced the 11th and 13th harmonics. The fifth and seventh harmonics, which theoretically do not exist, were observed. Imbalance of the transformer leakage inductances would be one reason.

Fig. 15 shows the measured $V_{i}$ vs. THD characteristics. THD strongly depends on $V_{i}$ and $\alpha$. The solid lines indicate theoretical $V_{i}$ values given by (5). They almost coincide with the measured optimal $V_{i}$ that minimizes current THD.

Fig. 16 compares the theoretical and measured optimal $V_{i}$ as a function of $\alpha$. Close agreement between them was observed. It is noted that THD took a minimum value at $\alpha=20^{\circ}$ without AVS and was close to the minimized value with AVS. This coincides with the simulation result in Fig. 7.

Fig. 17 shows the voltage and current waveforms of AVS at $\alpha=60^{\circ}$. The configuration of employed AVS was shown in Fig. 6, and the transformer having a turns-ratio of 2:1 was used. The upper trace shows the output voltage of the inverter $2 v_{i}$. It is pulse-width modulated with a carrier frequency of $10 \mathrm{kHz}$

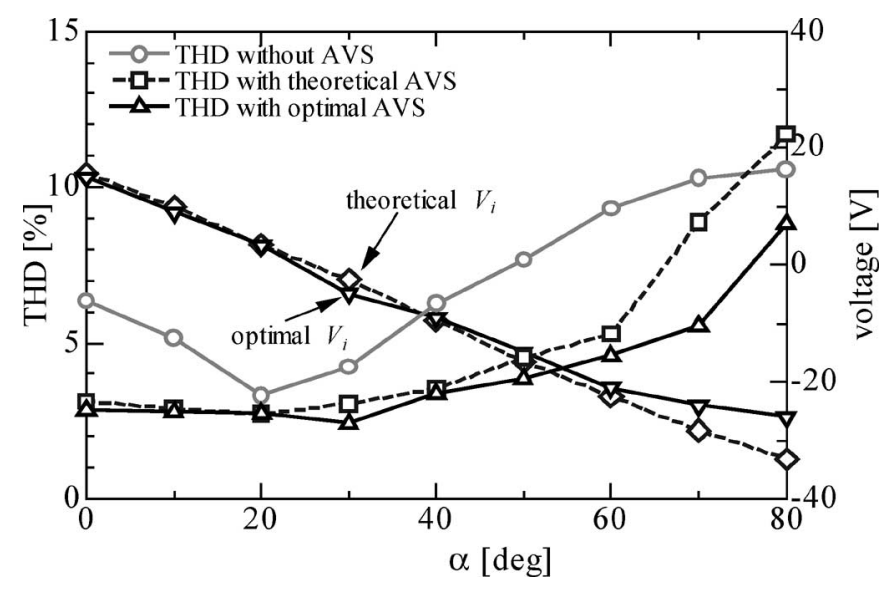

Fig. 16. Comparison of theoretical and measured characteristics, with optimal $V_{i}$ and current THD vs. $\alpha$.

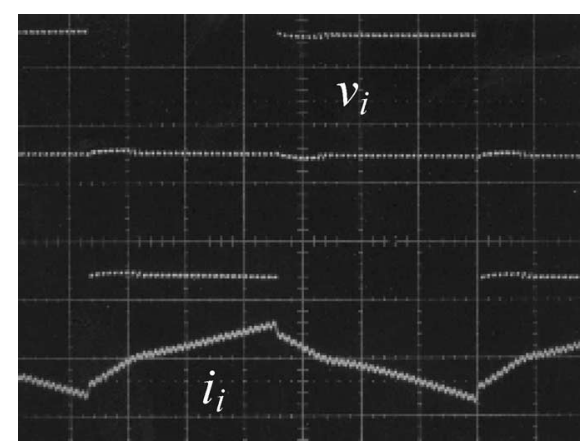

Fig. 17. Voltage and current waveforms of AVS at $\alpha=\pi / 3$; upper: $2 v_{i}, 50$ V/div; lower: $i_{i}, 5 \mathrm{~A} /$ div, $0.5 \mathrm{~ms} /$ div.

and dc input voltage of $V_{\mathrm{di} 0}=100 \mathrm{~V}$. The lower trace shows the inverter output current $i_{i}$. One can see that the measured $i_{i}$ is different from a pure triangular shape. This is because the approximation of the voltage $e_{22}-e_{11}$ in the dc equivalent circuit in Fig. 4 to a constant value is not exact if $\alpha$ is large. The approximation is done in the second term on the right-hand side of (3) when calculating (5).

\section{CONCLUSION}

This paper proposed a current harmonic distortion reduction method for parallel-connected 12-pulse choke-input phasecontrolled thyristor rectifiers. The method employs a singlephase square wave AVS and inserts it into the dc bus of the rectifier. If the AVS is appropriately controlled, this configuration enables one to reduce the harmonic distortion of the rectifier resultant input currents almost equivalent to that of a phase-controlled 24-pulse rectifier.

This paper theoretically investigates the principle of harmonic reduction especially in the 11th and 13th harmonics in the input currents, and presents how the AVS should be adjusted in relation to the load current and firing angle to get the best results in terms of harmonic reduction. The usefulness of the proposed configuration and control strategy of the auxiliary supply is verified by simulation and experimental results. The VA rating of the 
auxiliary supply is around $5 \%$ of that of the 12-pulse thyristor rectifier.

\section{REFERENCES}

[1] A. Siebert, A. Troedson, and S. Ebner, "AC to DC power conversion now and in the future," IEEE Trans. Ind. Appl., vol. 38, no. 4, pp. 934-940, Jul./Aug. 2002.

[2] D. E. Rice, "A detailed analysis of six-pulse converter harmonic currents," IEEE Trans. Ind. Appl., vol. 30, no. 2, pp. 294-304, Mar./Apr. 1994.

[3] IEEE Recommended Practices and Requirements for Harmonic Control in Electrical Power Systems, IEEE Standard 519, 1992.

[4] D. A. Paice, Power Electronic Converter Harmonic Multipulse Methods for Clean Power. New York: IEEE Press, 1996.

[5] J. R. Rodriguez, J. Pontt, C. Silva, E. P. Wiechmann, P. W. Hammond, F. W. Santucci, R. Alvarez, R. Musalem, S. Kouro, and P. Lezana, "Large current rectifiers: State of the art and future trends," IEEE Trans. Ind. Electron., vol. 52, no. 3, pp. 738-746, Jun. 2005.

[6] C. Rech and J. R. Pinheiro, "Line current harmonics reduction in multipulse connection of asymmetrically loaded rectifiers," IEEE Trans. Ind. Electron., vol. 52, no. 3, pp. 640-652, Jun. 2005.

[7] H. Akagi, "Active harmonic filters," in Proc. IEEE, Dec. 2005, vol. 93 , no. 12 , pp. 2128-2141.

[8] M. Rastogi, R. Naik, and N. Mohan, "Optimization of a novel DC link current modulated interface with 3-phase utility systems to minimize line current harmonics," in Proc. IEEE Power Electron. Spec. Conf., 1992, vol. 1, pp. 162-167.

[9] S. Kim, P. N. Enjeti, and P. Packebush, "A new approach to improve power factor and harmonics in a three-phase diode rectifier type utility interface," IEEE Trans. Ind. Appl., vol. 30, no. 5, pp. 1557-1564, Nov./Dec. 1994.

[10] L. Freitas, M. Simoes, C. Canesin, and L. Freitas, "Programable PFC based hybrid multipulse power rectifier for ultra clean power application," IEEE Trans. Power Electron., vol. 21, no. 4, pp. 959-966, Jul. 2006.

[11] F. Al-Haddad and R. Parimelalagan, "A new modulation technique for reducing the input current harmonics of a three-phase diode rectifier with capacitive load," IEEE Trans. Ind. Appl, vol. 33, no. 5, pp. 1185-1193, Sep./Oct. 1997.

[12] S. Choi, C. Won, and G. Kim, "A new three-phase harmonic-free rectification scheme based on zero-sequence current injection," IEEE Trans. Ind. Appl., vol. 41, no. 2, pp. 627-633, Mar./Apr. 2005.

[13] M. Rashid, Power Electronics Handbook. New York: Academic, 2001.

[14] B. K. Bose, Power Electronics and AC Drives. Englewood Cliffs, NJ: Prentice-Hall, 1986

[15] R. W. Erickson and D. Maksimovic, Fundamentals of Power Electronics. Norwell, MA: Kluwer, 2001.

[16] S. Miyairi, S. Iida, and K. Nakata, "New method for reducing harmonics improved in input and output of rectifier with interphase transformer," IEEE Trans. Ind. Appl., vol. IA-22, no. 5, pp. 790-797, Sep./Oct. 1986.

[17] S. Choi, P. Enjeti, H. Lee, and I. Pitel, "A new active interphase reactor for 12-pulse rectifiers provides clean power utility interface," IEEE Trans. Ind. Appl., vol. 32, no. 6, pp. 1304-1311, Nov./Dec. 1996.

[18] S. Masukawa and S. Iida, "A method for reducing harmonics in output voltages of a double-connected inverter," IEEE Trans. Power Electron., vol. 9, no. 5, pp. 543-550, Sep. 1994.

[19] Y. Nishida and M. Nakaoka, "A new harmonic reducing diode rectifier of capacitor input type for industrial high-voltage and high-power applica- tions," in Proc. IEEE Inst. Aeronaut. Sci. Annu. Meet., May 1998, vol. 1, pp. 552-558.

[20] H. Fujita and H. Akagi, "An approach to harmonic-free AC/DC power conversion for large industrial loads: The integration of a series active filter with a double-series diode rectifier," in Proc. IEEE Inst. Aeronaut. Sci. Annu. Meet., 1996, pp. 1040-1047.

[21] P. Cheng, S. Bhattacharya, and D. Divan, "Line harmonics reduction in high-power systems using square-wave inverters-based dominant harmonic active filter," IEEE Trans. Power Electron., vol. 14, no. 2, pp. 265272, Mar. 1999.

[22] T. Okuyama, "Diode rectifier system," Japanese Patent 10-80143, A, 1998.

[23] S. Fukuda and M. Ohta, "An auxiliary-supply-assisted twelve-pulse diode rectifier with reduced input current harmonics," in Proc. IEEE Inst. Aeronaut. Sci. Аnпи. Meet., Oct. 2004, vol. 1, p. 452.

[24] Y. Iwaji and T. Okuyama, "Thyristor converter system," Japanese Patent 10-295080, A, 1998.

[25] S. Fukuda and I. Hiei, "An auxiliary-supply-assisted input current harmonic reduction in 12-pulse thyristor rectifiers," in Proc. IEEE Power Electron. Drive Syst., Nov. 2005, vol. 2, pp. 854-859.

[26] T. Tanaka, N. Koshio, H. Akagi, and A. Nabae, "A novel method of reducing the supply current harmonics of a 12-pulse thyristor rectifier with an interface reactor," in Proc. IEEE Inst. Aeronaut. Sci. Annu. Meet., Oct. 1996, vol. 2, pp. 1256-1262.

[27] Deta sheets of ABB HiPak IGBT Module, 5SNA 2400E170100.

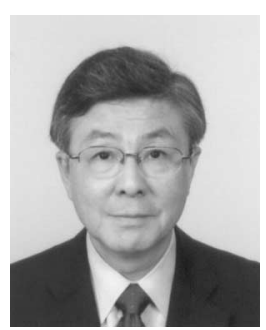

Shoji Fukuda (M'85-SM'96) received the M.E.E. and $\mathrm{Ph} . \mathrm{D}$. degrees in electrical engineering from Hokkaido University, Sapporo, Japan, in 1967 and 1977, respectively.

During 1967, he was with the Department of Electrical Engineering, Hokkaido University, where he was engaged in research on ac drives, pulse width modulation (PWM) control of rectifiers/inverters, and active filters.

Dr. Fukuda is a Member of the Institution of Electrical Engineers (IEE) of Japan and a member of the Japan Institute of Power Electronics.

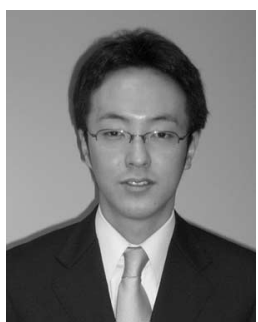

Issei Hiei was born in Shiga Prefecture, Japan, in 1980. He received the B.E.E. and M.E.E. degrees in system engineering from Hokkaido University, Sapporo, Japan, in 2004 and 2006, respectively.

During 2006, he was with Honda Motor Company Ltd., His current research interests include power converter control.

Mr. Hiei is a member of the Institution of Electrical Engineers (IEE) of Japan. 